OPEN ACCESS

Edited by:

Peng $X u$,

Xiamen University, China

Reviewed by:

Yun Li,

Ocean University of China, China

Costas S. Tsigenopoulos,

Hellenic Centre for Marine Research

(HCMR), Greece

${ }^{*}$ Correspondence:

Xiaohui Chen

cxiaohui416@hotmail.com

Qiong Shi

shiqiong@genomics.cn

Wenji Bian

js6060@sina.com

Xinxin You

youxinxin@genomics.cn

tThese authors have contributed equally to this work

Specialty section This article was submitted to

Livestock Genomics,

a section of the journal

Frontiers in Genetics

Received: 20 November 2018

Accepted: 06 March 2019

Published: 26 March 2019

Citation:

Zhang S, Zhang X, Chen X, XU T, Wang $M$, Qin $Q$, Zhong $L$, Jiang $H$, Zhu X, Liu H, Shao J, Zhu Z, Shi Q,

Bian W and You X (2019)

Construction of a High-Density

Linkage Map and QTL Fine Mapping for Growth- and Sex-Related Traits

in Channel Catfish (Ictalurus punctatus). Front. Genet. 10:251.

doi: 10.3389/fgene.2019.00251

\section{Construction of a High-Density Linkage Map and QTL Fine Mapping for Growth- and Sex-Related Traits in Channel Catfish (Ictalurus punctatus)}

\author{
Shiyong Zhang ${ }^{1,2,3+}$, Xinhui Zhang ${ }^{4 t}$, Xiaohui Chen ${ }^{2,3 *}$, Tengfei Xu ${ }^{4}$, Minghua Wang ${ }^{2,3}$,

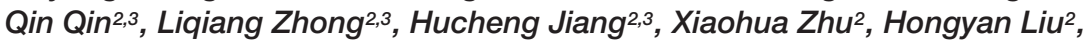 \\ Junjie Shao ${ }^{2}$, Zhifei Zhu ${ }^{5}$, Qiong Shi ${ }^{1,4 *}$, Wenji Bian ${ }^{2,3 *}$ and Xinxin You ${ }^{1,4 *}$
}

\begin{abstract}
${ }^{1}$ BGI Education Center, University of Chinese Academy of Sciences, Shenzhen, China, ${ }^{2}$ National Genetic Breeding Center of Channel Catfish, Freshwater Fisheries Research Institute of Jiangsu Province, Nanjing, China, ${ }^{3}$ The Jiangsu Provincial Platform for Conservation and Utilization of Agricultural Germplasm, Nanjing, China, ${ }^{4}$ Shenzhen Key Lab of Marine Genomics, Guangdong Provincial Key Lab of Molecular Breeding in Marine Economic Animals, BGl Academy of Marine Sciences, BGI Marine, Beijing Genomics Institute, Shenzhen, China, ${ }^{5}$ BGI-Zhenjiang Institute of Hydrobiology, Zheniiang, China
\end{abstract}

A high-density genetic linkage map is of particular importance in the fine mapping for important economic traits and whole genome assembly in aquaculture species. The channel catfish (Ictalurus punctatus), a species native to North America, is one of the most important commercial freshwater fish in the world. Outside of the United States, China has become the major producer and consumer of channel catfish after experiencing rapid development in the past three decades. In this study, based on restriction site associated DNA sequencing (RAD-seq), a high-density genetic linkage map of channel catfish was constructed by using single nucleotide polymorphisms (SNPs) in a $F_{1}$ family composed of 156 offspring and their two parental individuals. A total of 4,768 SNPs were assigned to 29 linkage groups (LGs), and the length of the linkage map reached 2,480.25 centiMorgans (CM) with an average distance of $0.55 \mathrm{cM}$ between loci. Based on this genetic linkage map, 223 genomic scaffolds were anchored to the 29 LGs of channel catfish, and a total length of $704.66 \mathrm{Mb}$ was assembled. Quantitative trait locus (QTL) mapping and genome-wide association analysis identified 10 QTLs of sex-related and six QTLs of growth-related traits at LG17 and LG28, respectively. Candidate genes associated with sex dimorphism, including spata2, spata5, sf3, zbtb38, and fox, were identified within QTL intervals on the LG17. A sex-linked marker with simple sequence repeats (SSR) in zbtb38 gene of the LG17 was validated for practical verification of sex in the channel catfish. Thus, the LG17 was considered as a sex-related LG. Potential growth-related genes were also identified, including important regulators such as megf9, npffr 1 , and gas 1 . In a word, we constructed the high-density genetic linkage map and developed the sex-linked marker in channel catfish, which are important genetic resources for future marker-assisted selection (MAS) of this economically important teleost.

Keywords: channel catfish, linkage map, quantitative trait locus (QTL), growth-related genes, sex-related marker 


\section{INTRODUCTION}

Genetic-map construction is a critically important tool for further genomic studies, as well as for genetic breeding of economically important aquatic species. It has been employed for genome assembly (Jiao et al., 2014), comparative genome analysis (Xiao et al., 2015; Zhu et al., 2015; Peng et al., 2016), and quantitative trait locus (QTL) identification for important economic traits (Liu F. et al., 2013; Zhang et al., 2018). In order to construct a genetic linkage map, it is necessary to develop a large number of molecular markers on examined families. Most of the early genetic linkage map constructions used amplified fragment length polymorphism (AFLP) and simple sequence repeats (SSR), but these maps had few molecular markers with low density (Zhang et al., 2011), which limited identification of QTL and related researches.

With the rapid development of next-generation sequencing (NGS), an increasing number of methodologies have been applied for cost-effective development and genotyping of thousands of single nucleotide polymorphisms (SNPs) in nonmodel animals, such as genome resequencing (Lijavetzky et al., 2007), transcriptome sequencing (Triwitayakorn et al., 2011; Xiao et al., 2015), genotyping-by-sequencing (GBS) (Poland et al., 2012), restriction site associated DNA sequencing (RAD-seq), and specific-locus amplified fragment (SLAF) sequencing (Sun X. et al., 2013). At present, the RAD-seq technology is a popular tool for establishment of high-density genetic linkage maps in many aquaculture species, such as Zhikong scallop (Chlamys farreri) (Jiao et al., 2014), mandarin fish (Siniperca chuatsi) (Lijavetzky et al., 2007), tilapia (Oreochromis niloticus L.) (Palaiokostas et al., 2013b), Asian seabass (Lates calcarifer) (Wang L. et al., 2015), and Chinese mitten crab (Eriocheir sinensis) (Cui et al., 2015).

High-quality genetic linkage maps can locate QTLs on corresponding genomes and facilitate marker-assisted selection (MAS) and breeding in many economically important aquaculture species. Sex is one of the most basic characteristics of organisms. Many species of teleost fish have sexually dimorphic growth patterns (Tong and Sun, 2015) with significant growth differences between male and female individuals, such as yellow catfish (Pelteobagrus fulvidraco) (Liu H. et al., 2013), Japanese flounder (Paralichthys olivaceus) (Van Ooijen, 2011), halfsmooth tongue sole (Cynoglossus semilaevis) (Song et al., 2012), and Atlantic halibut (Hippoglossus hippoglossus) (Palaiokostas et al., 2013a). Growth is also one of the most important economic traits for aquaculture fish species, was reported to be controlled by multi-gene and environmental effects (Feng et al., 2018) with extensive studies in many aquaculture fish species, such as rainbow trout (Sundin et al., 2005), salmon (Salmo salar) (Norman et al., 2012), and common carp (Cyprinus carpio) (Peng et al., 2016). In addition to QTL for growth and sex, QTL for stress responses, disease resistance, and cold tolerance have been mapped in other fish species (Ozaki et al., 2001; Cnaani et al., 2003; Fuji et al., 2006; Tripathi et al., 2009).

Traditional strategies for genetic improvement of growthrelated traits have mainly relied on phenotypic data, which increased time and cost for breeding. However, MAS using marker-linked QTLs has accelerated genetic improvement with high accuracy of selection. Since genetic linkage map and QTLs allow to identify molecular markers or candidate genes associated with traits (Mackay et al., 2009; Feng et al., 2018), they have become important MAS breeding tools in recent years.

As an important aquaculture species, channel catfish (Ictalurus punctatus) has been popular in the worldwide. Especially in the native United States, it accounts for more than $60 \%$ of the US annual aquaculture production (Liu, 2011). Since its introduction to China in 1984 , it has been promoted to many provinces in China, with an annual production of more than 200,000 tons. In the past decades, several linkage map and QTL studies (Waldbieser et al., 2001; Liu et al., 2003; Kucuktas et al., 2009; Li et al., 2015; Zeng et al., 2017) have been carried out to facilitate channel catfish genetic improvement and breeding programs. Previous reports confirmed that males of channel catfish grow generally faster than females under same culturing conditions (Beaver et al., 1966). Therefore, all-male monosex channel catfish has important economic values for development in aquaculture. A sex-linked marker for American strains of channel catfish was identified and the electrophoretic bands of PCR products were characterized (Ninwichian et al., 2012); however, the DNA variations of this marker should be further illustrated for validation in China strains. Meanwhile, it is necessary to establish a MAS breeding program for the channel catfish beforehand to improve the targeted economical traits. In this study, RAD-seq was employed to construct a high-density genetic linkage map, which was useful for subsequent construction of chromosome maps and identification of candidate sex-related and growth-related genes. Our present work confirms that a high-density genetic linkage map can provide a powerful tool for QTL fine mapping and genome-wide association study of economical traits.

\section{MATERIALS AND METHODS}

\section{Sample Collection and DNA Isolation}

A $F_{1}$ full-sib family of channel catfish was generated at National Genetics Breeding Center of Channel Catfish in Nanjing, Jiangsu Province, China, during June of 2015. Fertilized eggs were hatched with slow-flowing water $\left(23-27^{\circ} \mathrm{C}\right)$ in separate tanks. After approximately 1 week, a random collection of approximately 5,000 larvae was stocked in separate larvae-culture tanks $(3.0 \mathrm{~m} \times 1.0 \mathrm{~m} \times 0.5 \mathrm{~m})$. Zooplankton was fed at the first 10 days, and then with formula feed. After 20 days, a random collection of approximately 1,000 larvae was transferred to an outdoor pond (about 667 square meters) for further culturing. Until December 2016, these offspring individuals at the age of 18 months were measured for growth-related traits including body height $(\mathrm{BH})$, body length (BL), body weight (BW), and body width (WD), and the genders of these F1 individuals were also identified at the same time.

After investigating the relationships among the growthrelated traits with R3.3.1 software (Baayen, 2008) to calculate Pearson correlation coefficients, we randomly picked up 156 healthy individuals for sample collection. Fin clips of their parents and muscle tissues of these offspring were collected in 
absolute ethanol, and then stored in a $-20^{\circ} \mathrm{C}$ freezer before use. Genomic DNA was extracted using the established phenolchloroform protocol (Taggart et al., 1992). DNA quality was evaluated via the Qubit Fluorometer (Invitrogen, United States) and electrophoresis on a $0.6 \%$ agarose gel. All experiments were performed in accordance with the Regulations of the Animal Ethics Committee and were approved by the Institutional Review Board on Bioethics and Biosafety of Freshwater Fisheries Research Institute of Jiangsu Province (No. FT 18134).

\section{Construction and Sequencing of RAD Libraries}

DNAs of the total 158 individuals (156 offspring and two parents) were used to construct RAD libraries, which was prepared via a previously published protocol (Baird et al., 2008). In brief, each enzyme reaction system $(30 \mu \mathrm{L})$, containing $1 \mu \mathrm{g}$ of genomic DNA and $15 \mathrm{U}$ of EcoRI $(15 \mathrm{U} / \mu \mathrm{L}$, with the restriction site of $5^{\prime} \mathrm{G}^{\wedge} \mathrm{AATTC} 3^{\prime}$ ) (Thermo Scientific, Waltham, $\mathrm{MA}$, United States), was incubated at $65^{\circ} \mathrm{C}$ for $10 \mathrm{~min}$. Barcode adapters with a sample-specific nucleotide code were designed, following the standard Illumina adapters design flow. Unique barcode adapter $(10 \mu \mathrm{mol})$ for each DNA sample was added to individual reaction system. Twelve DNA samples were pooled per tube. In order to obtain more sequencing data for two parents, they were pooled in triplicates. Therefore, there were 162 DNA samples used for pooling. Fourteen pools were collected and the fragments at the size range of 300-500 bp were chosen. Fourteen libraries were independently sequenced using the 150-bp pairend sequencing method on an Illumina HiSeqX-ten platform (Illumina, San Diego, CA, United States).

\section{Filtering of Raw Data and Splitting of Barcode Reads}

After removal of sequencing adapters, low-quality reads (more than five positions with quality value less than 20, or more than $3 \%$ of unknown nucleotides) were filtered using the SOAPnuke software (Chen et al., 2018). The remained highquality reads were used for subsequent analysis. Clean reads from the same library were separated via a Perl script on the basis of their individual barcodes. Meanwhile, those reads with wrong barcodes (not matching to the expected) were also discarded.

\section{SNP Discovery and Genotyping}

Genome-wide SNPs were identified using a stringent SNP discovery filtering method within the software SOAPsnp (Li et al., 2009a). In order to obtain specific SNPs of the parents and the offspring, we employed SOAP2.22 (Li et al., 2009b) to align these high-quality paired-end RAD reads to the channel catfish reference genome, which was published previously (Chen et al., 2016). Based on our SOAP alignment results, we used SOAPsnp v1.05 to call SNPs. For quality control, we applied many criteria to filter SNPs, including (1) nucleotide quality more than 20; (2) depth between 3 and 300; (3) removal of reads that mapped to multiple sites; and (4) at least one heterozygote from parents. These identified SNP loci were finally separated into three segregation patterns, type $\operatorname{lm} \times 11$ or $n n \times n p(1: 1)$ or hk $\times$ hk $(1: 2: 1)$.

\section{Construction of the High-Density Genetic Map}

Linkage groups (LGs) were assigned using JoinMap4.1 software (Ooijen, 2006) under the CP algorithm, and Lep-Map (Rastas et al., 2013) was used to realize the genetic map construction. First, the Lep-Map filtering module was used to filter out markers via comparison of the offspring genotype distribution and the expected Mendelian proportions (segregation distortion test). The default value of the data tolerance $(P$-value $=0.01)$ was used to discard highly segregated markers $\left(\chi^{2}\right.$ test, $\left.P<0.01\right)$. Subsequently, the separate LGomosomes module was used to assign markers into LGs and then execute with logarithm of odds (LOD) scores for recombination fraction. A range of LOD scores from 5 to 15 incrementing by 1 were tested for linkage grouping. The final LOD score (15) was selected based on whether the number of LGs matched the number of chromosomes of channel catfish and the assembled chromosomes showed the 1:1 synteny relationship with the Liu et al. (2016) map. Finally, the Order Markers module was used to orientate markers within each LG, and the Kosambi mapping function was used to convert the recombination frequencies into map distances in centiMorgans (cM) (Kosambi, 2016).

\section{QTL Mapping for Growth- and Sex-Related Traits}

We employed MapQTL6.0 (Van Ooijen, 2011) to perform QTL analyses following the method of multiple QTL model (MQM). Regression algorithm was used for mapping quantitative trait loci in line crosses. The threshold for QTL significance was determined using a genome-wide permutation test with 200 iterations, and cofactors for MQM analyses were automatically selected with a $p$-value of 0.02. Significant LOD thresholds were calculated by permutation test of $\alpha<0.05$ and $n=1,000$ for significant linkages. The software also calculated phenotypic variation that resulted from growth- and sex-related QTLs. These markers were mapped on the channel catfish genome (Chen et al., 2016) and upstream and downstream coding genes were identified and subsequently searched against the database of nonredundant protein sequences $(\mathrm{Nr}$, cut-off value of $1 \mathrm{e}-10)$ at the National Center for Biotechnology Information (NCBI) using BLASTx to predict functions of these genes.

\section{Genome Scaffold Assembly, Synteny Analysis, and Identification of Potential Sex-Related and Growth-Related Genes}

Single nucleotide polymorphisms in the genetic linkage map were used for assembling of pseudo-chromosomes. To increase the accuracy of pseudo-chromosomes assembly, we chose at least two SNPs in each scaffold using custom Perl scripts. Based on genetic distances between SNP markers, we determined the position and orientation of each scaffold and anchored these scaffolds to construct pseudo-chromosomes. To perform the genome synteny analysis, genome sequences of zebrafish 
(Danio rerio) and channel catfish (Liu et al., 2016) were downloaded from the NCBI. Genome-wide alignments were performed using lastz software (Kurtz et al., 2004), and the best homology segments were selected using perl scripts. The final genomic synteny was visualized using the Circos software (Krzywinski et al., 2009).

\section{Identification, Verification, and Localization of a Sex-Specific Marker}

According to a previous report (Ninwichian et al., 2012), we obtained a 192-bp sex-related sequence of channel catfish by Sanger sequence. The specific primers, SexF $\left(5^{\prime}\right.$-TGAATGTGAGACTAACAGGAG-3 $\left.{ }^{\prime}\right)$ and SexR (5'ACATCGCTTTGAGAAGCTGCT-3'), were designed based on flanking sequences of this sex-linked marker using Primer3 (Koressaar and Remm, 2007) software. The forward primer was labeled with a fluorescent dye 5'6-FAM by Sangon Biotech Co. Ltd. (Shanghai, China). Subsequently, the designed specific primers were used for PCR amplification in 43 male and 53 female channel catfish individuals from two breeding populations. Each PCR reaction was done in a $20-\mu \mathrm{L}$ volume containing $1 \mu \mathrm{L}$ of $30-50 \mathrm{ng}$ of genomic DNA, $1 \mu \mathrm{L}$ of forward primer and reverse primer $(1.0 \mathrm{pmol} / \mathrm{L}), 10 \mu \mathrm{L} 2 \times$ Taq PCR MasterMix $\left[0.1 \mathrm{U}\right.$ Taq polymerase $\mu \mathrm{L}-1,5.0 \times 10^{-4} \mathrm{~mol} / \mathrm{L}$ dNTP each, $2.0 \times 10^{-2} \mathrm{~mol} / \mathrm{L}$ Tris- $\mathrm{HCl}(\mathrm{pH} 8.3), 0.1 \mathrm{~mol} / \mathrm{L}$ $\mathrm{KCl}, 3.0 \times 10^{-3} \mathrm{~mol} / \mathrm{L} \mathrm{MgCl}_{2} ;$ Vazyme, Nanjing, China], and sufficient $\mathrm{ddH}_{2} \mathrm{O}$. Touchdown PCR was initiated at $94^{\circ} \mathrm{C}$ for $30 \mathrm{~s}$. The annealing temperature of these reactions decreased from $60^{\circ} \mathrm{C}$ to a touchdown $50^{\circ} \mathrm{C}$ at the cooling rate of $1^{\circ} \mathrm{C}$ in every cycle; followed $94^{\circ} \mathrm{C}$ for $30 \mathrm{~s}, 55^{\circ} \mathrm{C}$ for $30 \mathrm{~s}, 72^{\circ} \mathrm{C}$ for $30 \mathrm{~s}, 20$ cycles; and final extension steps at $72^{\circ} \mathrm{C}$ for $10 \mathrm{~min}$. For fragment length analysis, PCR products were genotyped on a ABI PRISM 3730XL DNA Sequencer (Applied Biosystems, Foster City, CA, United States) with GS500 marker as an internal size standard. The allelic sizes were determined using GeneMarker version 1.5 (SoftGenetics LLC, State College, PA, United States).

\section{RESULTS}

\section{Characteristics of the Growth- and Sex-Related Traits}

Individuals in the mapping family had an average $\mathrm{BH}$ of $6.69 \pm 0.78 \mathrm{~cm}$, an average $\mathrm{BL}$ of $30.05 \pm 2.93 \mathrm{~cm}$, an average BW of $601.76 \pm 187.53 \mathrm{~g}$, and an average WD of $5.18 \pm 0.59 \mathrm{~cm}$. The growth-related traits showed strong correlation with each other $(r=0.8292-0.9312, P$-value $<0.001$ for all). The highest correlation value 0.9312 was observed between BW and BL (Table 1). In the mapping population, 74 and 82 individuals were identified as male and females, respectively, with a sex ratio of $1: 1.11$. Statistics on male and female growth data demonstrated that male individuals have larger $\mathrm{BL}, \mathrm{BH}$, body wide, and $\mathrm{BW}$ than female individuals (Table 2), indicating that males grow faster than females under the same culturing condition.

\section{Summary of the RAD Libraries}

A total of 14 RAD-seq libraries from two parents and their 156 offspring individuals were sequenced on an Illumina HiSeqX-ten platform to generated about 1.59 billion of 150 -bp pair-end reads. The DNA sequencing raw data have been deposited for public availability in CNSA (CNGB Nucleotide Sequence Archive) ${ }^{1}$ with the project no. CNP0000229. After subsequent filtering of lowquality reads, 1.42 billion of clean reads were remained. The number of clean reads per offspring individual was averaged to 8.66 million. Meanwhile, both the female and male parental data contained 28.76 and 25.64 million of clean reads, respectively.

\section{SNP Calling and Construction of the High-Resolution Genetic Linkage Map}

A total of 1,367,192 SNPs in all individuals were identified using SOAPSnp, in which 10,661 SNPs passed through the filtering criteria (see more details in section "Materials and Methods"). These SNPs were classified into three categories: paternal heterozygous ( $\mathrm{lm} \times 1 \mathrm{l}, 5,617 \mathrm{SNPs})$, maternal heterozygous ( $\mathrm{nn} \times \mathrm{np}, 4,915$ SNPs), and heterozygous in both (hk $\times \mathrm{hk}$, 129 SNPs). Among them, 4,768 SNPs were consistent with Mendelian segregation pattern, and then they were used for subsequent linkage map construction using a pseudo-testcross strategy (Shao et al., 2015).

These SNPs were finally grouped into 29 LGs (Table 3 and Figure 1), which is consistent with the reported haploid chromosome number of the channel catfish (Liu et al., 2016). The genetic linkage map spanned 2,480.25 cM with an average SNP interval of $0.55 \mathrm{cM}$. The genetic length of each LG ranged from 28.71 (LG27) to $141.1 \mathrm{cM}$ (LG22), with an average SNP distance of 0.21-1.01 cM (Table 3 and Figure 1).

${ }^{1}$ https://db.cngb.org/cnsa/

TABLE 1 | Pearson correlation coefficients for all pairwise combinations of the four examined traits.

\begin{tabular}{lcccc}
\hline Traits & BW & BL & BH & WD \\
\hline BW & 1 & 0.9312 & 0.8747 & 0.8847 \\
BL & 0.9312 & 1 & 0.8292 & 0.8318 \\
BH & 0.8747 & 0.8292 & 1 & 0.8612 \\
WD & 0.8847 & 0.8318 & 0.8612 & 1 \\
\hline
\end{tabular}

TABLE 2 | Significant growth difference between female and male channel catfish.

\begin{tabular}{lccc}
\hline Item & Male (mean) & Female (mean) & $\boldsymbol{P}$-value (t-test) \\
\hline $\mathrm{BW}(\mathrm{g})$ & $643 \pm 205.8^{* *}$ & $563 \pm 161.4$ & 0.007 \\
$\mathrm{BL}(\mathrm{cm})$ & $32.59 \pm 3.22^{*}$ & $31.56 \pm 2.57$ & 0.027 \\
$\mathrm{BH}(\mathrm{cm})$ & $6.83 \pm 0.83^{*}$ & $6.57 \pm 0.72$ & 0.038 \\
$\mathrm{WD}(\mathrm{cm})$ & $5.29 \pm 0.59^{*}$ & $5.08 \pm 0.56$ & 0.022
\end{tabular}

*Significant difference; **very significantly different. 
TABLE 3 | Characteristics of genetic linkage map and anchoring scaffolds of channel catfish.

\begin{tabular}{|c|c|c|c|c|c|c|}
\hline LG_ID & $\begin{array}{l}\text { Length of anchored } \\
\text { scaffolds (Mb) }\end{array}$ & $\begin{array}{c}\text { No. of anchored } \\
\text { genes }\end{array}$ & $\begin{array}{l}\text { No. of anchored } \\
\text { scaffolds }\end{array}$ & No. of SNPs & Distance (cM) & $\begin{array}{l}\text { Average inter-loci } \\
\text { distance (cM) }\end{array}$ \\
\hline LG1 & 32.97 & 939 & 22 & 308 & 109.18 & 0.35 \\
\hline LG2 & 11.3 & 300 & 3 & 67 & 60.85 & 0.91 \\
\hline LG3 & 25.4 & 643 & 6 & 138 & 29.01 & 0.21 \\
\hline LG4 & 16.9 & 501 & 5 & 186 & 77.46 & 0.42 \\
\hline LG5 & 22.99 & 647 & 7 & 153 & 101.21 & 0.66 \\
\hline LG6 & 22.73 & 595 & 11 & 183 & 96.57 & 0.52 \\
\hline LG7 & 25.49 & 714 & 11 & 144 & 76.81 & 0.53 \\
\hline LG8 & 24.2 & 661 & 4 & 156 & 88.71 & 0.56 \\
\hline LG9 & 31.5 & 783 & 12 & 175 & 100.47 & 0.57 \\
\hline LG10 & 33.31 & 743 & 7 & 205 & 99.39 & 0.48 \\
\hline LG11 & 18.72 & 408 & 5 & 143 & 73.32 & 0.51 \\
\hline LG12 & 22.8 & 622 & 10 & 419 & 111.54 & 0.27 \\
\hline LG13 & 40.9 & 961 & 10 & 200 & 66.76 & 0.33 \\
\hline LG14 & 36.44 & 905 & 9 & 171 & 49.21 & 0.28 \\
\hline LG15 & 18.73 & 411 & 11 & 143 & 70.69 & 0.49 \\
\hline LG16 & 7.23 & 215 & 1 & 166 & 94.6 & 0.56 \\
\hline LG17 & 30.04 & 655 & 10 & 181 & 78 & 0.43 \\
\hline LG18 & 32.68 & 864 & 9 & 155 & 110.03 & 0.7 \\
\hline LG19 & 28.52 & 837 & 4 & 120 & 99.71 & 0.83 \\
\hline LG20 & 22.94 & 649 & 12 & 141 & 78.59 & 0.55 \\
\hline LG21 & 14.47 & 438 & 2 & 111 & 69.52 & 0.62 \\
\hline LG22 & 32.78 & 618 & 6 & 318 & 141.1 & 0.44 \\
\hline LG23 & 16.91 & 402 & 3 & 63 & 23.23 & 0.36 \\
\hline LG24 & 33.41 & 790 & 7 & 152 & 136.71 & 0.89 \\
\hline LG25 & 17.44 & 475 & 8 & 136 & 112.19 & 0.82 \\
\hline LG26 & 23.50 & 614 & 5 & 125 & 125.9 & 1.01 \\
\hline LG27 & 8.43 & 189 & 5 & 62 & 28.71 & 0.46 \\
\hline LG28 & 22.67 & 788 & 8 & 116 & 75.76 & 0.65 \\
\hline LG29 & 29.17 & 794 & 10 & 131 & 95.02 & 0.72 \\
\hline Total & 704.66 & 18,161 & 223 & 4,768 & $2,480.25$ & - \\
\hline Average & 24.29 & 626 & 7 & 164 & 85.52 & 0.55 \\
\hline
\end{tabular}

The anchored genes and scaffolds are from the genome assembly (Chen et al., 2016).

\section{Fine QTL Mapping for Growth- and Sex-Related Traits}

In this study, four growth-related traits including BW, BL, $\mathrm{BH}$, and WD were measured. Six QTLs associated with growth-related traits were identified on the LG28, which were detected between the narrow span of 32.53-45.29 cM (Table 4). Among these QTLs, the highest LOD value of 4.29 (Figure 2A) was located at $37.46 \mathrm{cM}$ near the marker Scaffold53-3609071, which accounts for $11.8 \%$ of the phenotypic variation. No major locus explaining > $20 \%$ of the total variation was detected among these growthrelated QTLs.

Meanwhile, 10 significant QTLs for sex determination were detected on the LG17 of the channel catfish using permutation tests $(P<0.02$, LOD $>3.3)$. Among these QTLs, the highest LOD value of 31.01 (Figure 2B) was located at $53.39 \mathrm{cM}$ near the marker Scaffold55-2157602, which contributed to $59.5 \%$ of the phenotypic variation.

\section{Chromosomal Assembly and Comparative Genome Analysis}

Twenty-nine pseudo-chromosomes (Chr) of channel catfish with a total length of $704.66 \mathrm{Mb}$ were assembled, which comprised $83.39 \%$ of the assembled scaffold sequences (Chen et al., 2016) and 18,161 genes (a total number of 21,556 genes). The average pseudo-chromosome length was $24.29 \mathrm{Mb}$ with seven scaffolds. The smallest pseudochromosome was chr16 with $7.23 \mathrm{Mb}$ containing one scaffold, and the largest pseudo-chromosome was chr13 with $40.9 \mathrm{Mb}$ containing 10 scaffolds.

There were 16,197 synteny blocks between the assembled genomes of channel catfish and zebrafish, and 15 of the 29 LGs of channel catfish had relatively conserved collinear blocks on zebrafish chromosomes (Figure 3A). The total number of synteny blocks between our channel catfish assembly (Chen et al., 2016) and the assembly published by Liu et al. (2016) was 55,525. All chromosomes showing the 1:1 synteny relationship 


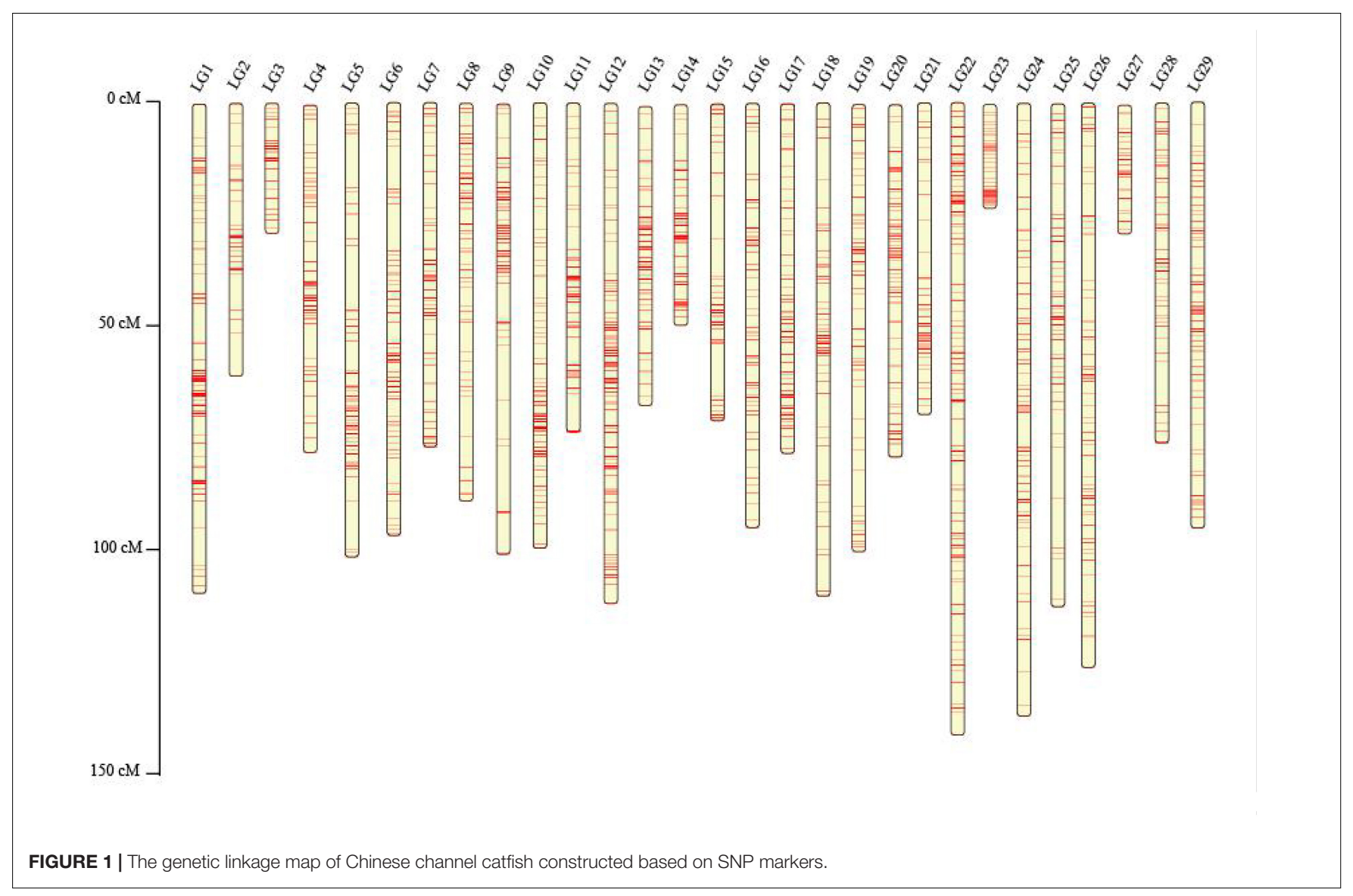

TABLE 4 | Characteristics of the growth- and sex-related QTLs in the channel catfish (LOD > 3.3).

\begin{tabular}{|c|c|c|c|c|c|c|}
\hline Trait & QTL & LG & Nearest marker & LOD & $\mathrm{Cl}(\mathrm{cM})$ & $\%$ Expl \\
\hline \multirow{7}{*}{ Sex } & qSEX_2 & 17 & Scaffold60-2211815 & 23.62 & $39.11-40.11$ & 49.8 \\
\hline & qSEX_4 & 17 & Scaffold60-2727790 & 19.1 & 33.19-33.69 & 42.7 \\
\hline & qSEX_5 & 17 & Scaffold55-2157602 & 31.01 & 53.39 & 59.5 \\
\hline & qSEX_6 & 17 & Scaffold60-1735567 & 28.8 & 59.77 & 56.8 \\
\hline & qSEX_8 & 17 & Scaffold11-8795560 & 26.73 & 70.31 & 54.1 \\
\hline & qSEX_9 & 17 & Scaffold11-3807312 & 23.36 & 76.38-76.92 & 49.4 \\
\hline & qSEX_10 & 17 & Scaffold11-2572525 & 23.14 & 74.38-75.38 & 49.1 \\
\hline \multirow[t]{3}{*}{ Growth } & qGW_1 & 28 & Scaffold53-3650014 & 3.33 & 32.53-32.74 & 9.3 \\
\hline & qGW_2 & 28 & Scaffold39-5862985 & 3.30 & $34.76-34.86$ & 9.1 \\
\hline & qGW_3 & 28 & Scaffold52-3364243 & 3.32 & 35.53 & 9.2 \\
\hline
\end{tabular}

GW, growth; Expl, percentage of explained phenotypic variation.

(Figure 3B). Figure 4 summarizes the distribution of SNPs, genes, GC content on $100-\mathrm{kb}$ genomic intervals, and interchromosomal relationships of our assembled channel catfish pseudo-chromosomes.

\section{Potential Candidate Genes for Sex}

\section{Dimorphism and Growth-Related Traits}

To further identify potential genes underlying sex dimorphisms, we used BLASTX to search gene sequences on the LG17 from 


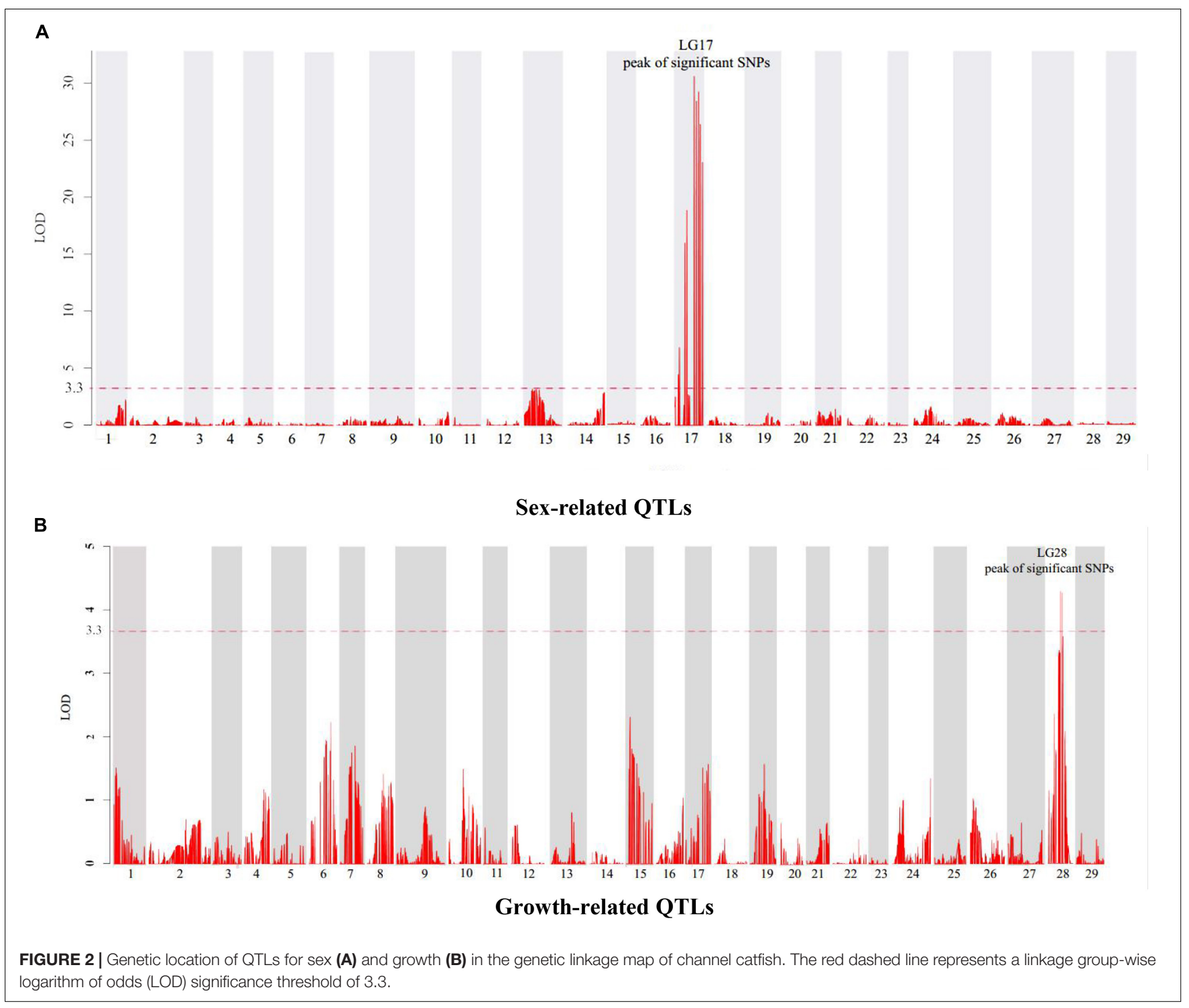

the QTL regions against the NCBI Nr database. Finally, 23 sexrelated genes were predicted, and they were previously reported to be involved in spermatogenesis, gonad sex determination, and testicular determination (Table 5). These genes included spermatogenesis-associated protein 2 (spata2), spata5, splicing factor 3 (sf3), and forkhead box $(f o x)$. Five sex-related genes including Wilms tumor protein 1-interacting protein (wt1), spata2, probable ATP-dependent DNA helicase DDX11 ( $d d x 11)$, zinc finger homeobox protein 3-like isoform X1 (zfhox3), and forkhead box protein F1 ( foxf1) were located near four sex-related QTLs (qSEX_6, qSEX_7, qSEX_8, and qSEX_10) (Figure 5A).

We screened our reference genome and collected proteincoding genes from the growth-related QTL regions. Three growth-related genes, including multiple epidermal growth factor-like domains protein 9 (megf9), neuropeptide FF receptor 1 (npffr1), and growth arrest-specific protein 1 (gas1), were found in two (qGW_1 and qGW_3) of the six growth-related QTL regionso (Table 5). Among these genes, $n p f f r 1$ is receptor of neuropeptide FF and RFamide-related peptide ( $r f r p$ ), which are involved in control of feeding behavior both in certain invertebrates and in vertebrates (Dockray, 2004; Bechtold and Luckman, 2007).

These candidate genes localized on the LG17 and LG28 may involve in the genetic control of sex- and growth-related traits. Detailed functions are worthy of further investigation for genetic breeding of channel catfish.

\section{A Sex-Linked Marker Was Verified in the Channel Catfish}

According to previously reported molecular marker (Ninwichian et al., 2012), we obtained a 192-bp fragment by Sanger sequencing. Subsequently, we used the clean reads of the samples in this study to perform multiple sequence alignments with this special sex-linked sequence. We observed that the sex-linked locus consists of three 

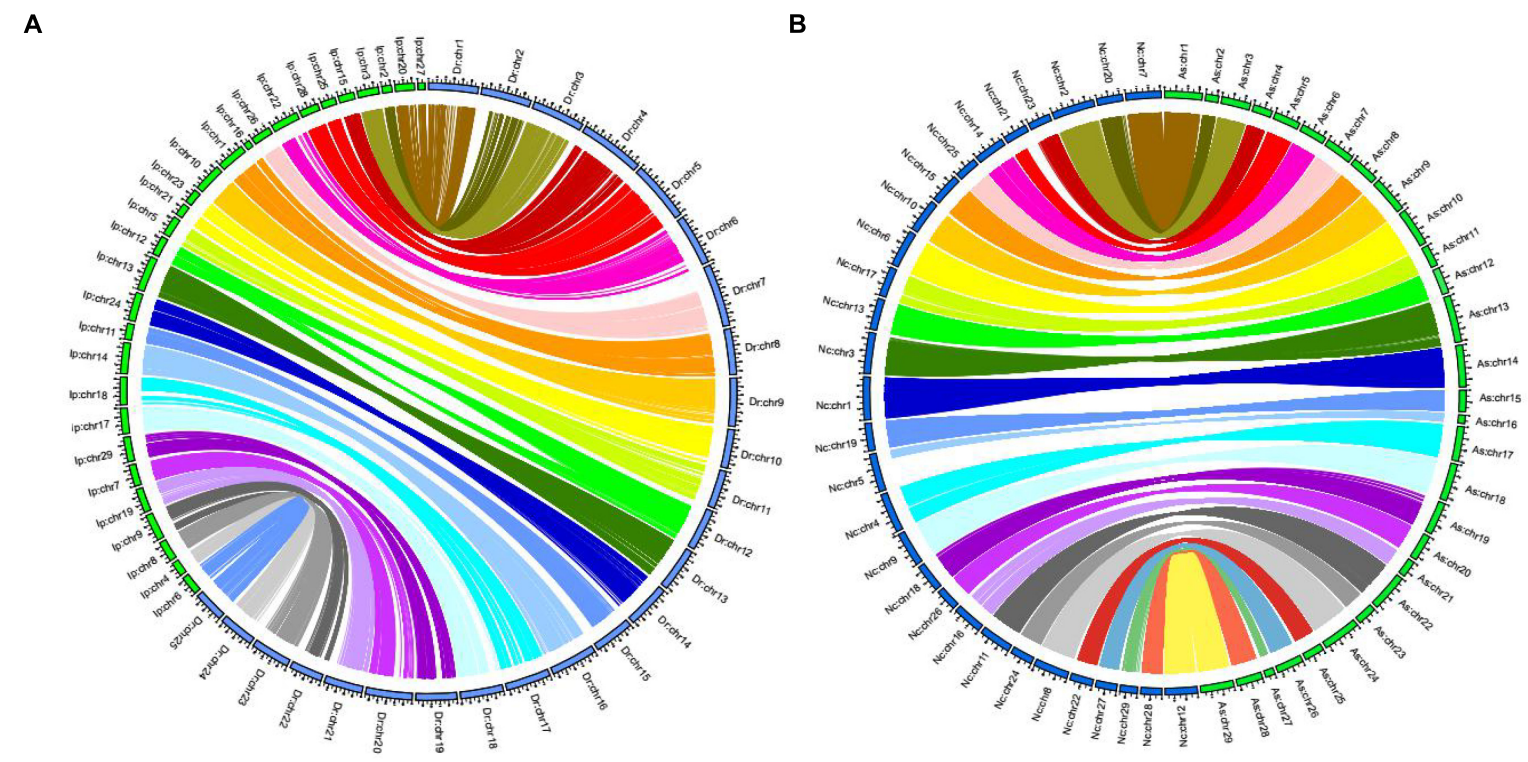

FIGURE 3 | (A) Circos diagram representing syntenic relationships between channel catfish (Ip: Ictalurus punctatus, assembled by Chen et al., 2016) (green) and zebrafish (Dr: Danio rerio) (blue). (B) Circos diagram representing syntenic relationships between two assembled channel catfish chromosomes (green, assembled by us; blue, from Liu et al., 2016).

TABLE 5 | Annotation of growth- and sex-related candidate genes in the genome of channel catfish.

\begin{tabular}{|c|c|c|c|c|}
\hline Gene ID & LG & Abbreviations & Gene name in $\mathrm{nr}$ database & Reference \\
\hline CF_GLEAN_10004009 & LG17 & foxg1 & Forkhead box protein G1-like & Hu et al., 2017 \\
\hline CF_GLEAN_10009162 & LG17 & kif23 & Kinesin-like protein KIF23 isoform X1 & Sun F. et al., 2013 \\
\hline CF_GLEAN_10009169 & LG17 & iqch & IQ domain-containing protein $\mathrm{H}$ isoform $\mathrm{X} 1$ & Sun F. et al., 2013 \\
\hline CF_GLEAN_10009212 & LG17 & fox 11 & Forkhead box protein L1 & Hu et al., 2017 \\
\hline CF_GLEAN_10016328 & LG17 & cdyl2 & Chromodomain Y-like protein 2 & Lahn et al., 2001 \\
\hline CF_GLEAN_10016329 & LG17 & cdyl2 & Chromodomain Y-like protein 2 & Lahn et al., 2001 \\
\hline CF_GLEAN_10016347 & LG17 & irf8 & Interferon regulatory factor 8 isoform $\mathrm{X} 1$ & Martinez et al., 2014 \\
\hline CF_GLEAN_10016349 & LG17 & foxf1 & Forkhead box protein F1 & Hu et al., 2017 \\
\hline CF_GLEAN_10016370 & LG17 & zfhox3 & Zinc finger homeobox protein 3-like isoform X1 & Mardon and Page, 1989 \\
\hline CF_GLEAN_10016375 & LG17 & $d d \times 11$ & Probable ATP-dependent DNA helicase DDX11 & Sun F. et al., 2013 \\
\hline CF_GLEAN_10007358 & LG17 & $w t 1$ & Wilms tumor protein 1-interacting protein & Lin et al., 2017 \\
\hline CF_GLEAN_10009192 & LG17 & $s f 3 b$ & Splicing factor $3 \mathrm{~B}$ subunit 3 & Lin et al., 2017 \\
\hline CF_GLEAN_10009153 & LG17 & wnt2 & Protein Wnt-2 & Luo et al., 2015 \\
\hline CF_GLEAN_10016543 & LG17 & rnf141 & Ring finger protein 141 & Sun F. et al., 2013 \\
\hline CF_GLEAN_10016386 & LG17 & celf6 & CUGBP Elav-like family member 6 & Blech-Hermoni and Ladd, 2015 \\
\hline CF_GLEAN_10016430 & LG17 & map3k10 & Mitogen-activated protein kinase kinase kinase 10 & Bogani et al., 2009 \\
\hline CF_GLEAN_10009166 & LG17 & pias1 & E3 SUMO-protein ligase PIAS1 & Oh et al., 2007 \\
\hline CF_GLEAN_10009228 & LG28 & gas1 & Growth arrest-specific protein 1 & Del Sal et al., 1992 \\
\hline CF_GLEAN_10009299 & LG28 & megfg & Multiple epidermal growth factor-like domains protein 9 & Thakker et al., 2018 \\
\hline CF_GLEAN_10009247 & LG28 & npffr1 & Neuropeptide FF receptor 1 & Peng et al., 2016 \\
\hline
\end{tabular}




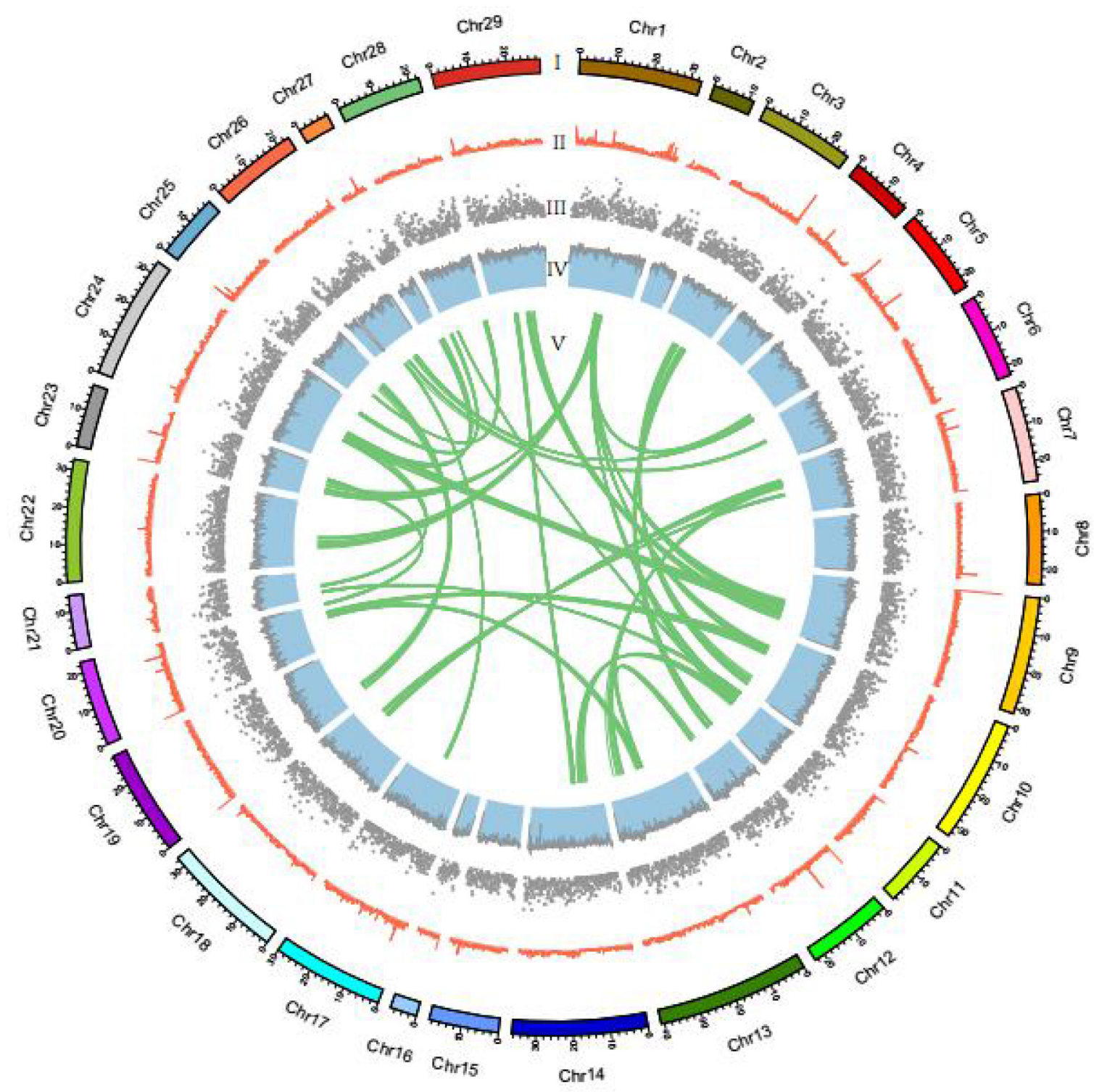

FIGURE 4 | Circos atlas representation of the pseudo-chromosome information. (I) The length of each pseudo-chromosome. (II) Density of SNP distribution in each 100-kb genomic interval. (III) Density of gene distribution in each 100-kb genomic interval. (IV) GC content of 100-kb genomic intervals. (V) Schematic presentation of major interchromosomal relationships in the channel catfish genome.

types of allele, including no deletion (allele G1), 3bp deletion [one (TAA) repeat; allele G2], and 6-bp deletion [two (TAA) repeats; allele G3] in the SSR marker, respectively (Figures $\mathbf{5 C , D}$ ).

The 6-bp deletion allele presented in all male individuals but not in any of the females (Figures 5C,D), thus it could definitely distinguish male and female individuals. Chromosome location of this sex-linked SSR marker clearly marked it on the LG17 of channel catfish, within the non-coding region of zinc finger and BTB domain-containing protein 38 (zbtb38), which is approximately $25 \mathrm{~kb}$ in length and consists of six exons and five introns (Figure 5B). Furthermore, to verify the sexlinked SSR marker, we designed fluorescent primers to perform
PCR amplification in 43 male and 53 female catfish individuals from two other breeding populations. The PCR results matched phenotypes with a $100 \%$ overall accuracy.

\section{DISCUSSION}

A genetic linkage map can provide important genomic information and allow for exploration of QTL, which can be used to maximize the selection of target traits in breeding animals. Availability of a large number of genetic markers is essential for constructing a good genetic linkage map and for QTL mapping of available genetic traits. High-density 


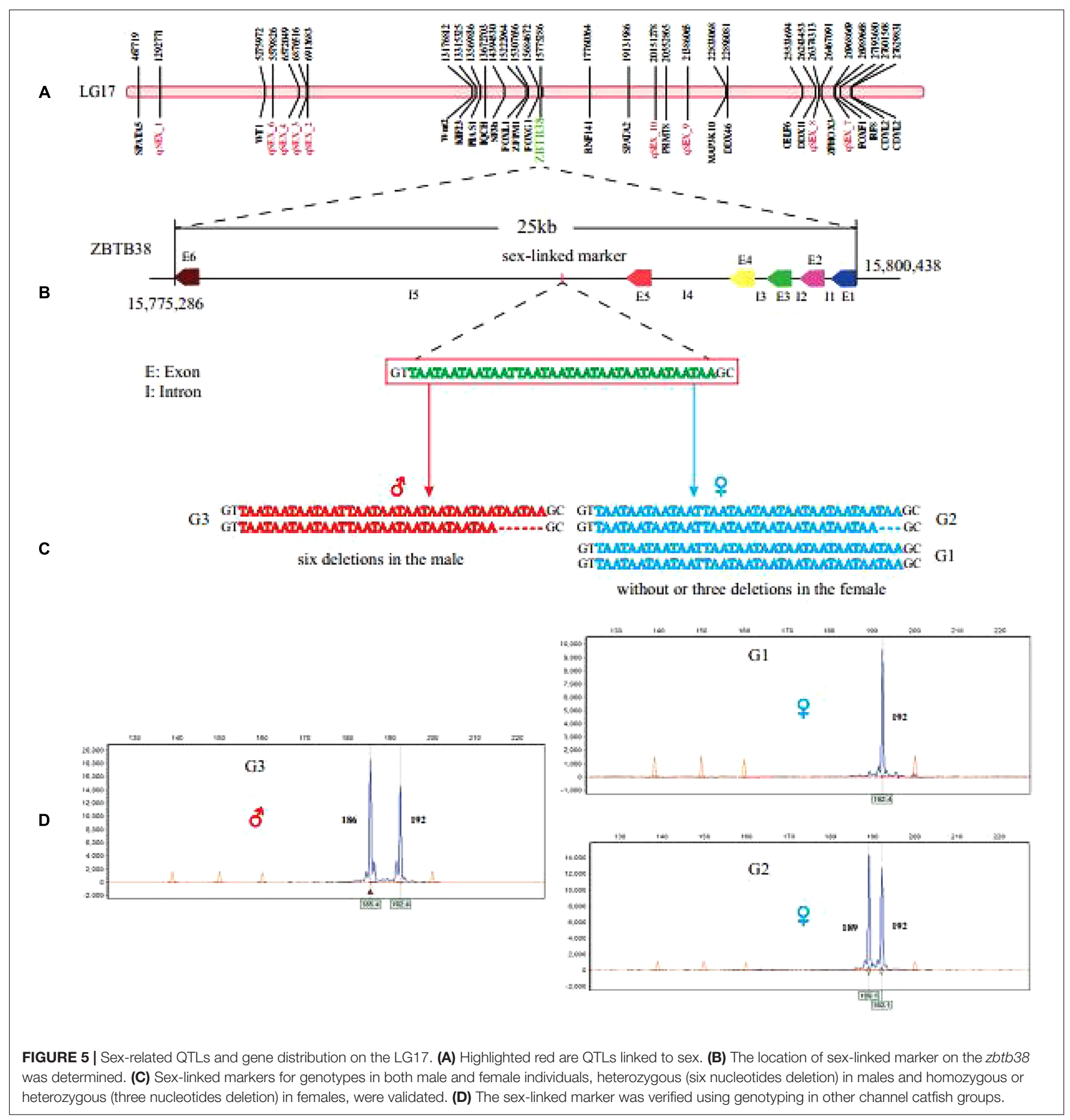

linkage maps and growth/sex-related QTLs were analyzed using RAD sequencing in several aquatic animals, such as genetic linkage map construction in orange-spotted grouper (Epinephelus coioides) (4,608 SNPs) (You et al., 2013), genetic map and sex-/growth-related QTL in turbot (Scophthalmus maximus) (6,647 SNPs) (Wang W. et al., 2015), blunt snout bream (Megalobrama amblycephala) (14,648 SNPs) (Wan et al., 2017), mandarin fish (S. chuatsi) (3,283 SNPs) (Sun et al., 2017), common carp (C.c. haematopterus) (7,820 SNPs and 295 SSRs)
(Feng et al., 2018), and pompano (Trachinotus blochii) (12,358 SNPs) (Zhang et al., 2018).

In the present study for channel catfish, we employed the RAD sequencing technology to construct a high-density genetic linkage map with 4,768 SNPs, reaching the total length to 2,480.25 $\mathrm{cM}$ with an average SNP distance of $0.55 \mathrm{cM}$. Using the markers to target specific scaffolds from previous study (Chen et al., 2016), we anchored a total number of 223 scaffolds in the channel catfish 
genome assembly to 29 LGs. Approximately $704.66 \mathrm{Mb}$ (83.39\%) of the assembled genome sequences were assigned to the 29 LGs with identification of 18,161 genes (84.25\%). Interestingly, in previous work (Chen et al., 2016), a female individual collecting from a local breeding stock in China was used for genome sequencing, and the assembly genome size was $845 \mathrm{Mb}$. However, in another published study of channel catfish genome using a doubled haploid female individual from the United States (Liu et al., 2016), a $783-\mathrm{Mb}$ genome was assembled. The remarkable different genome size may be generated from the different source of sequencing samples.

Many species of teleost fish have sex dimorphic growth patterns (Mei and Gui, 2015), and there are significant growth differences between males and females (Gui and Zhu, 2012; Liu F. et al., 2013).Therefore, in some species, production of monosex populations is desirable for economic values. In this study, we observed that males of the Chinese channel catfish have significant differences in $\mathrm{BW}$ and $\mathrm{BH}$ compared with females $(P$-value $<0.05$, Table 2$)$, and males exhibited much faster growth than females under the same culturing condition. This sexual dimorphism was also determined in other fish species, such as yellow catfish ( $P$. fulvidraco) (Liu H. et al., 2013) and Nile tilapia (O. niloticus) (Lee et al., 2011). The high-density genetic linkage map generated in present study provided useful data for QTL fine mapping of important economically traits (especially growth- and sex-related) in channel catfish.

Growth and sex are the most important traits for cultured fish species. Based on established genetic linkage maps, researchers have determined many practical QTLs for sex/growth traits. For example, in mandarin fish (S. chuatsi) one significant QTL for sex determination was identified on LG23; genotypes of all the female fish on r1_33008 marker were heterozygous, and all males were homozygous, thus this sex-specific marker can be used to identify male and female individuals of mandarin fish; meanwhile, 11 significant QTLs for growth traits were also detected on four LGs (Sun et al., 2017). Similarly, in our present study, 11 significant QTLs associated with sex-related trait at LOD $\geq 3.3$ were detected on the LG17, contributing to 12.3$59.5 \%$ of the phenotypic variation in channel catfish. This finding was confirmed in other fish species, such as Atlantic halibut (H. hippoglossus) (Palaiokostas et al., 2013a) and gilthead sea bream (Sparus aurata) (Loukovitis et al., 2011).

In contrast, sex-related QTLs of some other fish species were detected to be distributed on different LGs. In the blunt snout bream (M. amblycephala), three QTLs related to gonad development were detected on LG13, LG12, and LG1 (Wan et al., 2017). In the tilapia, sex-linked QTLs were detected on at least three LGs (LG1, LG3, and LG23; Lee et al., 2003; Cnaani et al., 2004; Eshel et al., 2012). These results suggest involvement of multiple chromosomes or LGs in sex relation and provide support to the polygenic sex determination in fishes. Sex determination of channel catfish probably is maledominant $(\mathrm{XX} / \mathrm{XY})$, due to sex ratios of offspring both in interspecific hybridization (I. punctatus $Q \times$ Ictalurus furcatus $\sigma^{\text {T }}$ ) and intraspecific hybridization of channel catfish close to $1: 1$, and the offspring in gynogenetic families were all females (Goudie et al., 1995). Similar to other fish species, the channel catfish sex chromosomes ( $\mathrm{X}$ and $\mathrm{Y}$ ) is difficult to be distinguished based on current karyotype analysis technologies. Therefore, identification of sex-specific markers and QTLs is a necessary prerequisition for uncovering sex determination mechanisms and associated genes, as well as proceeding sex-transformation and sex control tests.

Sex-specific markers have been identified in more than 20 economic aquaculture species to date by the strategies of AFLP and NGS. In the present study, 23 genes related to sex development were detected on the LG17, such as spata (related to sperm production; Sun F. et al., 2013; Chen et al., 2015), $w t 1$ (early establishment of gonad; Lin et al., 2017), and foxl1 (sex hormone regulation; Hu et al., 2017). The result is similar to tilapia, in which 51 sex-determination genes were annotated in the sex region on scaffold 101 (Eshel et al., 2012). In our current study, all sex-related QTLs are located on the same LG17 suggesting that a single chromosome may be involved in sex determination (Figure 3). To validate a previously reported sex-specific marker in channel catfish, we extracted those malespecific tags presented in all male individuals but not in any of females. Finally, we obtained one SSR marker with 6-bp deletion presented in all male $z b t b 38$ gene. Results from fluorescent PCRcapillary gel electrophoresis also confirmed the male-specific SSR marker. Likewise, sex-specific SSR markers have been reported in half-smooth tongue sole (C. semilaevis) (Chen et al., 2012) and kiwifruit (Actinidia chinensis Planchon) (Zhang et al., 2015), and they were used to distinguish male and female in practical breeding programs.

The good resolution and high density of our genetic linkage map provide an effective support for QTL mapping of economically traits, as well as for genome assembly. QTL fine mapping and positional cloning of candidate genes have been an efficient approach for breeding programs in aquaculture animals, especially for investigation of quantitative traits (Xiao et al., 2015; Yu et al., 2015; Peng et al., 2016). Interestingly, in our present study, six QTLs associated with growth traits $(\mathrm{BL}, \mathrm{BH}, \mathrm{BW}$, and $\mathrm{WD})$ were identified to cluster at a narrow linkage span (32.53-45.29 cM) of the LG28. We screened the reference genome (Chen et al., 2016) and identified three proteincoding genes from this growth-related QTL region, providing potential tools for molecular breeding of new variants with growth superiority.

\section{CONCLUSION}

In the present study, we employed RAD sequencing to construct a high-density genetic linkage map with 4,768 SNPs for the channel catfish. Ten sex-related QTLs were detected on the LG17, on which 23 genes related to sex development were annotated, such as spata, wt1, and foxl1. Six QTLs for growth were detected on the LG28, on which three growth-related genes were identified within the QTL intervals. A previously reported sex-linked marker was confirmed on the LG17, which can effectively identify male and female individuals of channel catfish from difference genetic resources. In summary, we provide a valuable genetic 
resource for future molecular breeding of this economically important fish species.

\section{DATA AVAILABILITY}

The datasets generated for this study can be found in CNGB Nucleotide Sequence Archive (https://db.cngb.org/cnsa/), CNP0000229.

\section{AUTHOR CONTRIBUTIONS}

$\mathrm{XY}, \mathrm{SZ}, \mathrm{QS}, \mathrm{WB}$, and XC conceived the ideas and designed the investigations. XZ, TX, and SZ analyzed the data. SZ, MW, QQ, LZ, and HJ collected and processed the samples. HL, JS,

\section{REFERENCES}

Baayen, R. H. (2008). Analyzing Linguistic Data: A Practical Introduction to Statistics Using R. Cambridge: Cambridge University Press. doi: 10.1017/ CBO9780511801686

Baird, N. A., Etter, P. D., Atwood, T. S., Currey, M. C., Shiver, A. L., Lewis, Z. A., et al. (2008). Rapid SNP discovery and genetic mapping using sequenced RAD markers. PLoS One 3:e3376. doi: 10.1371/journal.pone.0003376

Beaver, J. A., Sneed, K. E., and Dupree, H. K. (1966). The difference in growth of male and female channel catfish in hatchery ponds. Prog. Fish Cult. 28, 47-50. doi: 10.1577/1548-8640(1966)28[47:TDIGOM]2.0.CO;2

Bechtold, D. A., and Luckman, S. M. (2007). The role of RFamide peptides in feeding. J. Endocrinol. 192, 3-15. doi: 10.1677/JOE-06-0069

Blech-Hermoni, Y., and Ladd, A. N. (2015). Identification of transcripts regulated by CUG-BP, Elav-like family member 1 (CELF1) in primary embryonic cardiomyocytes by RNA-seq. Genom Data 6, 74-76. doi: 10.1016/j.gdata.2015. 08.014

Bogani, D., Siggers, P., Brixey, R., Warr, N., Beddow, S., Edwards, J., et al. (2009). Loss of mitogen-activated protein kinase kinase kinase 4 (MAP3K4) reveals a requirement for MAPK signalling in mouse sex determination. PLoS Biol. 7:e1000196. doi: 10.1371/journal.pbio.1000196

Chen, S., Ji, X., Shao, C., Li, W., Yang, J., Liang, Z., et al. (2012). Induction of mitogynogenetic diploids and identification of WW super-female using sexspecific SSR markers in half-smooth tongue sole (Cynoglossus semilaevis). Mar. Biotechnol. 14, 120-128. doi: 10.1007/s10126-011-9395-2

Chen, X., Mei, J., Wu, J., Jing, J., Ma, W., Zhang, J., et al. (2015). A comprehensive transcriptome provides candidate genes for sex determination/differentiation and SSR/SNP markers in yellow catfish. Mar. Biotechnol. 17, 190-198. doi: 10.1007/s10126-014-9607-7

Chen, X., Zhong, L., Bian, C., Xu, P., Qiu, Y., You, X., et al. (2016). High-quality genome assembly of channel catfish, Ictalurus punctatus. Gigascience 5:39. doi: 10.1186/s13742-016-0142-5

Chen, Y., Shi, C., Huang, Z., Zhang, Y., Li, S., Li, Y., et al. (2018). SOAPnuke: a MapReduce acceleration-supported software for integrated quality control and preprocessing of high-throughput sequencing data. Gigascience 7, 1-6. doi: 10.1093/gigascience/gix120

Cnaani, A., Hallerman, E. M., Ron, M., Weller, J. I., Indelman, M., Kashi, Y., et al. (2003). Detection of a chromosomal region with two quantitative trait loci, affecting cold tolerance and fish size, in an F2 tilapia hybrid. Aquaculture 223, 117-128. doi: 10.1016/S0044-8486(03)00163-7

Cnaani, A., Zilberman, N., Tinman, S., Hulata, G., and Ron, M. (2004). Genome-scan analysis for quantitative trait loci in an F2 tilapia hybrid. Mol. Genet. Genomics 272, 162-172. doi: 10.1007/s00438-0041045-1

Couderc, J., Godt, D., Zollman, S., Chen, J., Li, M., Tiong, S., et al. (2002). The bric a brac locus consists of two paralogous genes encoding $\mathrm{BTB} / \mathrm{POZ}$ domain and $\mathrm{ZZ}$ performed the experiments. $\mathrm{XZ}, \mathrm{SZ}$, and $\mathrm{XY}$ wrote the manuscript. XY and QS revised the manuscript. All authors read and approved the final manuscript for publication.

\section{FUNDING}

This project was supported by Major Project for New Cultivar Breeding of Jiangsu Province (No. PZCZ201741), China Agriculture Research System (No. CARS-46), Jiangsu Fisheries Research System (No. JFRS-05), Research Fund for the 333 Project of Jiangsu Province (No. BRA2018377), Shenzhen Special Program for Development of Strategic Emerging and Future Industries (No. 20170428173357698), and Shenzhen Special Program for Development of Emerging Strategic Industries (No. JSGG20170412153411369).

proteins and acts as a homeotic and morphogenetic regulator of imaginal development in Drosophila. Development 129, 2419-2433.

Cui, Z., Hui, M., Liu, Y., Song, C., Li, X., Li, Y., et al. (2015). High-density linkage mapping aided by transcriptomics documents ZW sex determination system in the Chinese mitten crab Eriocheir sinensis . Heredity 115, 206-215. doi: 10.1038/hdy.2015.26

Del Sal, G., Ruaro, M. E., Philipson, L., and Schneider, C. (1992). The growth arrest-specific gene, gas1, is involved in growth suppression. Cell 70, 595-607. doi: 10.1016/0092-8674(92)90429-G

Dockray, G. J. (2004). The expanding family of -RFamide peptides and their effects on feeding behaviour. Exp. Physiol. 89, 229-235. doi: 10.1113/expphysiol.2004. 027169

Eshel, O., Shirak, A., Weller, J., Hulata, G., and Ron, M. (2012). Linkage and physical mapping of sex region on LG23 of Nile tilapia (Oreochromis niloticus). G3 2, 35-42. doi: 10.1534/g3.111.001545

Feng, X., Yu, X., Fu, B., Wang, X., Liu, H., Pang, M., et al. (2018). A high-resolution genetic linkage map and QTL fine mapping for growth-related traits and sex in the Yangtze River common carp (Cyprinus carpio haematopterus ). BMC Genomics 19:230. doi: 10.1186/s12864-018-4613-1

Fuji, K., Kobayashi, K., Hasegawa, O., Coimbra, M. R. M., Sakamoto, T., and Okamoto, N. (2006). Identification of a single major genetic locus controlling the resistance to lymphocystis disease in Japanese flounder (Paralichthys olivaceus). Aquaculture 254, 203-210. doi: 10.1016/j.aquaculture.2005.11.024

Goudie, C. A., Simco, B. A., Davis, K. B., and Liu, Q. (1995). Production of gynogenetic and polyploid catfish by pressure-induced chromosome set manipulation. Aquaculture 133, 185-198. doi: 10.1016/0044-8486(94)00367-W

Gui, J., and Zhu, Z. (2012). Molecular basis and genetic improvement of economically important traits in aquaculture animals. Chin. Sci. Bull. 57, 1751-1760. doi: 10.1007/s11434-012-5213-0

Hu, Q., Xiao, H., Wang, Q., Tian, H., and Meng, Y. (2017). Identification and expression of forkhead box genes in the Chinese giant salamander Andrias davidianus. Reprod. Fertil. Dev. doi: 10.1071/RD17049 [Epub ahead of print].

Jiao, W., Fu, X., Dou, J., Li, H., Su, H., Mao, J., et al. (2014). High-resolution linkage and quantitative trait locus mapping aided by genome survey sequencing: building up an integrative genomic framework for a bivalve mollusc. DNA Res. 21, 85-101. doi: 10.1093/dnares/dst043

Koressaar, T., and Remm, M. (2007). Enhancements and modifications of primer design program Primer3. Bioinformatics 23, 1289-1291. doi: 10.1093/ bioinformatics/btm091

Kosambi, D. D. (ed.) (2016). The Estimation of Map Distances from Recombination Values. New Delhi: Springer, 125-130. doi: 10.1007/978-81-322-3676-4_16

Krzywinski, M., Schein, J., Birol, I., Connors, J., Gascoyne, R., Horsman, D., et al. (2009). Circos: an information aesthetic for comparative genomics. Genome Res. 19, 1639-1645. doi: 10.1101/gr.092759.109

Kucuktas, H., Wang, S. L., Li, P., He, C. B., Xu, P., Sha, Z. X., et al. (2009). Construction of genetic linkage maps and comparative genome analysis of 
catfish using gene-associated markers. Genetics 181, 1649-1660. doi: 10.1534/ genetics.108.098855

Kurtz, S., Phillippy, A., Delcher, A. L., Smoot, M., Shumway, M., Antonescu, C., et al. (2004). Versatile and open software for comparing large genomes. Genome Biol. 5:R12. doi: 10.1186/gb-2004-5-2-r12

Lahn, B. T., Pearson, N. M., and Jegalian, K. (2001). The human Y chromosome, in the light of evolution. Nat. Rev. Genet. 2, 207-216. doi: 10.1038/35056058

Lee, B. Y., Coutanceau, J. P., Ozouf-Costaz, C., D'cotta, H., Baroiller, J. F., and Kocher, T. D. (2011). Genetic and physical mapping of sex-linked AFLP markers in Nile tilapia (Oreochromis niloticus $</ \mathrm{i}>$ ). Mar. Biotechnol. 13, 557-562. doi: 10.1007/s10126-010-9326-7

Lee, B. Y., Penman, D., and Kocher, T. (2003). Identification of a sex determining region in Nile tilapia (Oreochromis niloticus) using bulked segregant analysis. Anim. Genet. 34, 379-383. doi: 10.1046/j.1365-2052.2003.01035.x

Li, R., Li, Y., Fang, X., Yang, H., Wang, J., and Kristiansen, K. (2009a). SNP detection for massively parallel whole-genome resequencing. Genome Res. 19, 1124-1132. doi: 10.1101/gr.088013.108

Li, R., Yu, C., Li, Y., Lam, T. W., Yiu, S. M., Kristiansen, K., et al. (2009b). SOAP2: an improved ultrafast tool for short read alignment. Bioinformatics 25, 1966-1967. doi: 10.1093/bioinformatics/btp336

Li, Y., Liu, S. K., Qin, Z. K., Waldbieser, G., Wang, R. J., Sun, L. Y., et al. (2015). Construction of a high-density, high-resolution genetic map and its integration with BAC-based physical map in channel catfish. DNA Res. 22, 39-52. doi: 10.1093/dnares/dsu038

Lijavetzky, D., Cabezas, J. A., Ibanez, A., Rodriguez, V., and Martinez-Zapater, J. M. (2007). High throughput SNP discovery and genotyping in grapevine (Vitis vinifera L. ) by combining a re-sequencing approach and SNPlex technology. BMC Genomics 8:424. doi: 10.1186/1471-2164-8-424

Lin, R., Wang, L., Zhao, Y., Gao, J., and Chen, Z. (2017). Gonad transcriptome of discus fish (Symphysodon haraldi) and discovery of sex-related genes. Aquacult. Res. 48, 5993-6000. doi: 10.1111/are.13424

Liu, F., Sun, F., Li, J., Xia, J. H., Lin, G., Tu, R. J., et al. (2013). A microsatellite-based linkage map of salt tolerant tilapia (Oreochromis mossambicusx Oreochromis spp. $</ \mathrm{i}>$ ) and mapping of sex-determining loci. BMC Genomics 14:58. doi: 10.1186/1471-2164-14-58

Liu, H., Guan, B., Xu, J., Hou, C., Tian, H., and Chen, H. (2013). Genetic manipulation of sex ratio for the large-scale breeding of YY super-male and XY all-male yellow catfish (Pelteobagrus fulvidraco(Richardson)). Mar. Biotechnol. 15, 321-328. doi: 10.1007/s10126-012-9487-7

Liu, Z. (2011). Development of genomic resources in support of sequencing, assembly, and annotation of the catfish genome. Comp. Biochem. Phys. D 6, 11-17. doi: 10.1016/j.cbd.2010.03.001

Liu, Z., Karsi, A., Li, P., Cao, D., and Dunham, R. (2003). An AFLP-based genetic linkage map of channel catfish (Ictalurus punctatus) constructed by using an interspecific hybrid resource family. Genetics 165, 687-694.

Liu, Z., Liu, S., Yao, J., Bao, L., Zhang, J., Li, Y., et al. (2016). The channel catfish genome sequence provides insights into the evolution of scale formation in teleosts. Nat. Commun. 7:11757. doi: 10.1038/ncomms11757

Loukovitis, D., Sarropoulou, E., Tsigenopoulos, C. S., Batargias, C., Magoulas, A., Apostolidis, A. P., et al. (2011). Quantitative trait loci involved in sex determination and body growth in the gilthead sea bream (Sparus aurata L. ) through targeted genome scan. PLoS One 6:e16599. doi: 10.1371/journal.pone. 0016599

Luo, D., Liu, Y., Chen, J., Xia, X., Cao, M., Cheng, B., et al. (2015). Direct production of XY(DMY-) sex reversal female medaka (Oryzias latipes ) by embryo microinjection of TALENs. Sci. Rep. 5:14057. doi: 10.1038/srep14057

Mackay, T. F., Stone, E. A., and Ayroles, J. F. (2009). The genetics of quantitative traits: challenges and prospects. Nat. Rev. Genet. 10, 565-577. doi: 10.1038/ $\operatorname{nrg} 2612$

Mardon, G., and Page, D. C. (1989). The sex-determining region of the mouse Y chromosome encodes a protein with a highly acidic domain and 13 zinc fingers. Cell 56, 765-770. doi: 10.1016/0092-8674(89)90680-6

Martinez, P., Vinas, A. M., Sanchez, L., Diaz, N., Ribas, L., and Piferrer, F. (2014). Genetic architecture of sex determination in fish: applications to sex ratio control in aquaculture. Front. Genet. 5:340. doi: 10.3389/fgene.2014.00340

Mei, J., and Gui, J. F. (2015). Genetic basis and biotechnological manipulation of sexual dimorphism and sex determination in fish. Sci. China Life Sci. 58, 124-136. doi: 10.1007/s11427-014-4797-9
Ninwichian, P., Peatman, E., Perera, D., Liu, S., Kucuktas, H., Dunham, R., et al. (2012). Identification of a sex-linked marker for channel catfish. Anim. Genet. 43, 476-477. doi: 10.1111/j.1365-2052.2011.02276.x

Norman, J. D., Robinson, M., Glebe, B., Ferguson, M. M., and Danzmann, R. G. (2012). Genomic arrangement of salinity tolerance QTLs in salmonids: a comparative analysis of Atlantic salmon (Salmo salar) with Arctic charr (Salvelinus alpinus) and rainbow trout (Oncorhynchus mykiss ). BMC Genomics 13:420. doi: 10.1186/1471-2164-13-420

Oh, H. J., Kido, T., and Lau, Y. F. C. (2007). PIAS1 interacts with and represses SOX9 transactivation activity. Mol. Reprod. Dev. 74, 1446-1455. doi: 10.1002/ $\operatorname{mrd} .20737$

Ooijen, J. (2006). JoinMap4. 0 software for the calculation of genetic linkage maps in experimental populations. Kyazma BV, Wageningen, NetherlandsVoorrips RE (2002) MapChart: software for the graphical presentation of linkage maps and QTLs. Theor. Appl. Genet. 124, 323332.

Ozaki, A., Sakamoto, T., Khoo, S., Nakamura, K., Coimbra, M., Akutsu, T., et al. (2001). Quantitative trait loci (QTLs) associated with resistance/susceptibility to infectious pancreatic necrosis virus (IPNV) in rainbow trout (Oncorhynchus mykiss ). Mol. Genet. Genomics 265, 23-31. doi: 10.1007/s0043800 00392

Palaiokostas, C., Bekaert, M., Davie, A., Cowan, M. E., Oral, M., Taggart, J. B., et al. (2013a). Mapping the sex determination locus in the Atlantic halibut (Hippoglossus hippoglossus ) using RAD sequencing. BMC Genomics 14:566. doi: 10.1186/1471-2164-14-566

Palaiokostas, C., Bekaert, M., Khan, M. G. Q., Taggart, J. B., Gharbi, K., Mcandrew, B. J., et al. (2013b). Mapping and validation of the major sex-determining region in Nile tilapia (Oreochromis niloticus L. ) Using RAD Sequencing. PLoS One 8:e68389. doi: 10.1371/journal.pone.0068389

Peng, W., Xu, J., Zhang, Y., Feng, J., Dong, C., Jiang, L., et al. (2016). An ultrahigh density linkage map and QTL mapping for sex and growth-related traits of common carp (Cyprinus carpio ). Sci. Rep. 6:26693. doi: 10.1038/srep26693

Poland, J. A., Brown, P. J., Sorrells, M. E., and Jannink, J.-L. (2012). Development of high-density genetic maps for barley and wheat using a novel two-enzyme genotyping-by-sequencing approach. PLoS One 7:e32253. doi: 10.1371/journal. pone.0032253

Rastas, P., Paulin, L., Hanski, I., Lehtonen, R., and Auvinen, P. (2013). Lep-MAP: fast and accurate linkage map construction for large SNP datasets. Bioinformatics 29, 3128-3134. doi: 10.1093/bioinformatics/ btt563

Shao, C., Niu, Y., Rastas, P., Liu, Y., Xie, Z., Li, H., et al. (2015). Genome-wide SNP identification for the construction of a high-resolution genetic map of Japanese flounder (Paralichthys olivaceus ): applications to QTL mapping of Vibrio anguillarum disease resistance and comparative genomic analysis. DNA Res. 22, 161-170. doi: 10.1093/dnares/dsv001

Song, W., Li, Y., Zhao, Y., Liu, Y., Niu, Y., Pang, R., et al. (2012). Construction of a high-density microsatellite genetic linkage map and mapping of sexual and growth-related traits in half-smooth tongue sole (Cynoglossus semilaevis ). PLoS One 7:e52097. doi: 10.1371/journal.pone.0052097

Sun, C., Niu, Y., Ye, X., Dong, J., Hu, W., Zeng, Q., et al. (2017). Construction of a high-density linkage map and mapping of sex determination and growthrelated loci in the mandarin fish (Siniperca chuatsi ). BMC Genomics 18:446. doi: 10.1186/s12864-017-3830-3

Sun, F., Liu, S., Gao, X., Jiang, Y., Perera, D., Wang, X., et al. (2013). Male-biased genes in catfish as revealed by RNA-Seq analysis of the testis transcriptome. PLoS One 8:e68452. doi: 10.1371/journal.pone.0068452

Sun, X., Liu, D., Zhang, X., Li, W., Liu, H., Hong, W., et al. (2013). SLAF-seq: an efficient method of large-scale de novo snp discovery and genotyping using high-throughput sequencing. PLoS One 8:e58700. doi: 10.1371/journal.pone. 0058700

Sundin, K., Brown, K. H., Drew, R. E., Nichols, K. M., Wheeler, P. A., and Thorgaard, G. H. (2005). Genetic analysis of a development rate QTL in backcrosses of clonal rainbow trout, Oncorhynchus mykiss. Aquaculture 247, 75-83. doi: 10.1016/j.aquaculture.2005.02.054

Taggart, J., Hynes, R., Prodöuhl, P., and Ferguson, A. (1992). A simplified protocol for routine total DNA isolation from salmonid fishes. J. Fish Biol. 40, 963-965. doi: 10.1111/j.1095-8649.1992.tb02641.x

Thakker, S., Strahan, R. C., Scurry, A. N., Uppal, T., and Verma, S. C. (2018). KSHV LANA upregulates the expression of epidermal growth factor like domain 7 
to promote angiogenesis. Oncotarget 9, 1210-1228. doi: 10.18632/oncotarget. 23456

Tong, J., and Sun, X. (2015). Genetic and genomic analyses for economically important traits and their applications in molecular breeding of cultured fish. Sci. China Life Sci. 58, 178-186. doi: 10.1007/s11427-015-4804-9

Tripathi, N., Hoffmann, M., Willing, E. M., Lanz, C., Weigel, D., and Dreyer, C. (2009). Genetic linkage map of the guppy, Poecilia reticulata, and quantitative trait loci analysis of male size and colour variation. Proc. Biol. Sci. 276, $2195-$ 2208. doi: 10.1098/rspb.2008.1930

Triwitayakorn, K., Chatkulkawin, P., Kanjanawattanawong, S., Sraphet, S., Yoocha, T., Sangsrakru, D., et al. (2011). Transcriptome sequencing of Hevea brasiliensis for development of microsatellite markers and construction of a genetic linkage map. DNA Res. 18, 471-482. doi: 10.1093/dnares/dsr034

Van Ooijen, J. (2011). MapQTL 6: Software for the Mapping of Quantitative Trait Loci in Experimental Populations of Diploid Species. Wageningen: Kyazma B.V.

Waldbieser, G., Bosworth, B. G., Nonneman, D. J., and Wolters, W. R. (2001). A microsatellite-based genetic linkage map for channel catfish, Ictalurus punctatus. Genetics 158, 727-734.

Wan, S. M., Liu, H., Zhao, B. W., Nie, C. H., Wang, W. M., and Gao, Z. X. (2017). Construction of a high-density linkage map and fine mapping of QTLs for growth and gonad related traits in blunt snout bream. Sci. Rep. 7:46509. doi: 10.1038/srep46509

Wang, L., Wan, Z. Y., Bai, B., Huang, S. Q., Chua, E., Lee, M., et al. (2015). Construction of a high-density linkage map and fine mapping of QTL for growth in Asian seabass. Sci. Rep. 5:16358. doi: 10.1038/srep16358

Wang, W., Hu, Y., Ma, Y., Xu, L., Guan, J., and Kong, J. (2015). Highdensity genetic linkage mapping in turbot (Scophthalmus maximus L.) based on SNP markers and major sex- and growth-related regions detection. PLoS One 10:e0120410. doi: 10.1371/journal.pone. 0120410

Xiao, S., Wang, P., Zhang, Y., Fang, L., Liu, Y., Li, J. T., et al. (2015). Gene map of large yellow croaker (Larimichthys crocea) provides insights into teleost genome evolution and conserved regions associated with growth. Sci. Rep. 5:18661. doi: 10.1038/srep18661

You, X., Shu, L., Li, S., Chen, J., Luo, J., Lu, J., et al. (2013). Construction of highdensity genetic linkage maps for orange-spotted grouper Epinephelus coioides using multiplexed shotgun genotyping. BMC Genet. 14:113. doi: 10.1186/14712156-14-113
Yu, Y., Zhang, X., Yuan, J., Li, F., Chen, X., Zhao, Y., et al. (2015). Genome survey and high-density genetic map construction provide genomic and genetic resources for the Pacific White Shrimp Litopenaeus vannamei. Sci. Rep. 5:15612. doi: 10.1038/srep15612

Zeng, Q. F., Fu, Q., Li, Y., Waldbieser, G., Bosworth, B., Liu, S. K., et al. (2017). Development of a $690 \mathrm{~K} \mathrm{SNP}$ array in catfish and its application for genetic mapping and validation of the reference genome sequence. Sci. Rep. 7:40347. doi: 10.1038/srep40347

Zhang, G., Zhang, X., Ye, H., Jiang, S., Yu, H., Li, J., et al. (2018). Construction of high-density genetic linkage maps and QTL mapping in the golden pompano. Aquaculture 482, 90-95. doi: 10.1016/j.aquaculture.2017. 09.011

Zhang, Q., Liu, C., Liu, Y., Vanburen, R., Yao, X., Zhong, C., et al. (2015). High-density interspecific genetic maps of kiwifruit and the identification of sex-specific markers. DNA Res. 22, 367-375. doi: 10.1093/dnares/ dsv019

Zhang, Y., Xu, P., Lu, C., Kuang, Y., Zhang, X., Cao, D., et al. (2011). Genetic linkage mapping and analysis of muscle fiber-related QTLs in common carp (Cyprinus carpio L. ). Mar. Biotechnol. 13, 376-392. doi: 10.1007/s10126-0109307-x

Zhu, C., Tong, J., Yu, X., and Guo, W. (2015). Comparative mapping for bighead carp (Aristichthys nobilis ) against model and non-model fishes provides insights into the genomic evolution of cyprinids. Mol. Genet. Genomics 290, 1313-1326. doi: 10.1007/s00438-015-0992-Z

Conflict of Interest Statement: The authors declare that the research was conducted in the absence of any commercial or financial relationships that could be construed as a potential conflict of interest.

The handling Editor declared a past co-authorship with one of the authors XY.

Copyright (c) 2019 Zhang, Zhang, Chen, Xu, Wang, Qin, Zhong, Jiang, Zhu, Liu, Shao, Zhu, Shi, Bian and You. This is an open-access article distributed under the terms of the Creative Commons Attribution License (CC BY). The use, distribution or reproduction in other forums is permitted, provided the original author(s) and the copyright owner(s) are credited and that the original publication in this journal is cited, in accordance with accepted academic practice. No use, distribution or reproduction is permitted which does not comply with these terms. 